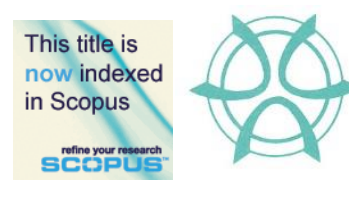

PLANNING MALAYSIA:

Journal of the Malaysian Institute of Planners

VOLUME 15 ISSUE 1 (2017), Page 221 - 228

\title{
THE BENEFITS OF RIVER INDICATORS TO ASSESS THE ECOLOGICAL STATUS OF IIUM CAMPUS
}

\author{
Nor Zalina Harun', Mazlina Mansor², \& Safiah Abu Noh \\ ${ }^{1,2,3}$ Kuliyyah of Architecture and Environmental Design \\ INTERNATIONAL ISLAMIC UNIVERSITY MALAYSIA
}

\begin{abstract}
The concept of sustainable campus has emerged from the social, economic and environmental impacts due to anthropogenic activities around the world. One of the initiatives of sustainable campus is the application of ecological indicators. The indicators provide information about the current condition and early warning on the possible risks of environmental impacts to the campus environment. However, lack of understanding on the values of natural ecosystem in campus and the lack of proper planning has led to the depletion of natural ecosystem. The study seeks to examine river degradation in IIUM campus and to explore the benefits of river indicators towards achieving IIUM as an ecologically sustainable campus. Data were gathered using a qualitative approach involving three methods of data collection namely: (i) document analysis, (ii) semi-structured interview and (iii) site inventory. The finding reveals that the application of river channel morphology indicators is an important basis for physical planning in making a campus ecologically sustainable. Further analysis suggests that the suitable indicators to assess the condition of IIUM River are the river channel morphology indicators such as width, depth, channel pattern and slope ratio. The process of selecting the indicators are carried out based on six criteria of good indicators discussed in this study. The study concluded that the application of river channel morphology indicators is a critical process in physical planning of a sustainable campus as it contributes in preventing the loss of natural ecosystem and it offers a credible basis for creating a conducive place for campus residents.
\end{abstract}

Keyword: IIUM campus, sustainable, ecological indicator, river

Date Received: $30^{\text {th }}$ April 2016

Date of Acceptance: $30^{\text {th }}$ October 2016 
Nor Zalina Harun, Mazlina Mansor, \& Safiah Abu Noh

The Benefits of River Indicators to Assess the Ecological Status of IIUM Campus

\section{INTRODUCTION}

The concept of sustainable development is an approach of making economic, social and environmental resources available for current and future generations. This concept has been implemented throughout the world as a response to many environmental degradation. Nowadays, the world faces numerous challenges that threaten to undermine the welfare of people all over the world. Issues like urban sprawl, congestion, waste and global warming has alarmed many urban planners and encouraged them to apply evolving notions of sustainability in city planning. As a result, many actions and policies have been developed to cater the issues of social, environmental and economic sustainability, especially in the urban contact.

The concept of sustainable urban development can be applied at any scale of development from a global scale to as small as institutional scale such as a campus of higher learning institution. Accordingly, a campus today is recognised as a vital platform where all new information and efforts to improve quality of life without compromising the needs for future demands can be disseminated (United Nations Environment Program, 2014). Significantly, an ideal campus is supposed to be an entity that can be an inspiration for many organizations in implementing efforts towards achieving sustainable development.

In Malaysia, three campuses have implemented the use of ecological indicator for their sustainable campus development. They are Universiti Kebangsaan Malaysia, Universiti Malaysia Sabah and Universiti Sains Malaysia. Among the three universities, four aspects that are often highlighted in their sustainability efforts are energy, water, transportation, and waste management (Zen et al., 2013; Saadatian et al., 2010).

This study contends that a tool for assessing the current condition of the natural ecosystems could help to predict any changes of the ecosystem state, as it is significant to maintain the natural ecosystem in order to create a conducive environment that supports learning, teaching, innovation and research. However, lack of awareness and consideration in maintaining the health of the river ecosystem in IIUM has led to degradation of the ecosystem, which contributes to many environmental impacts such as flash flood. In this case, the need of a tool to assess the river condition is vital to provide information, in order to avoid severe environmental impact on campus. Initial study revealed that the main trigger of the degradation of the river is because of the physical changes of the river. Therefore, this research was set out to identify the condition and factors of river changes and the framework of selecting ecological indicators for sustainable campus by concentrating on the river channel morphology.

\section{Ecologically Sustainable Campus and Its Environment}

Managing campuses by taking into account the environmental aspect is a must today. Ecologically sustainable campus is basically motivated by the idea that the 
PLANNING MALAYSIA

Journal of the Malaysia Institute of Planners (2017)

campus is expected to be a comfortable, clean, sound, beautiful and healthy place for knowledge seekers. By managing campus physical aspect, it will provide a healthy environment that is vital for the wellbeing of the campus residents. As a result, a good environment in campus will foster academic performance, and social and personal development by providing a place for students to get the opportunity to form an identity and sense of community of the institution.

\section{The Concept of Sustainable Development}

Sustainability or sustainable development has widely emerged in many areas of human civilization. It has started many years ago and continuously disseminated especially during 1987 when Brundtland Report was presented during the World Commission on Environment and Development Conference (WCED, 1987). The concept of sustainable development is actually emerged from the awareness about the importance of preservation and maintenance of natural resources. Since then, numerous initiatives have been taken at local, national and global levels in an effort to tackle diverse aspects of the environmental disputes (Mebratu, 1998). According to WCED (1987), sustainability can be defined as an approach that serves the needs of the present without neglecting the ability of future generations to fulfil their own needs. Brundtland's definition of sustainability has inspired many policymakers, environmentalists and researchers to further improve the inclusive definition of sustainability, resulting in a wide variety of meanings and interpretations.

\section{Sustainable Campus}

The sustainability concept evidently is applicable to any scale of development including institution like university. University is seen to be a key player in the global transition towards sustainable development. With its population and activities held in campus, it is recognized that its decisions and actions have a very significant impact on the environmental, economic and social aspects at present and in the future. University is seen to be accountable to perform as role model for the bigger community. It is because university is an ideal platform to disseminate the idea of sustainability (Howitt, \& Rickards, 2013). The future leaders that study in the campus are valuable assets and are hoped to spread the sustainability concept after they graduated especially in their working environment. Therefore, it is recommended that this is accomplished through the education of future generations about sustainability practices into their own university operation.

Campos (2008) who views the work of Le Corbusier in 1936, highlights that the campus is a place which students enjoy the pleasant stage of life in the ambience of a paradise. Here, the term campus is envisioned as a physical boundary used by students for a certain period of study that have a comfortable and conducive learning environment. The visualization of a sustainable campus 
Nor Zalina Harun, Mazlina Mansor, \& Safiah Abu Noh

The Benefits of River Indicators to Assess the Ecological Status of IIUM Campus

must be envisioned by the character of a paradise which highlights the exquisite of its ecological aspect. Therefore, campus should serve as a place with vibrant environment for learning because knowledge seeking should be the most enjoyable juncture in human life that depicts a character of a paradise.

Therefore, an ideal ecologically sustainable campus is a campus that resides picturesque landscape blended with a great diversity of ecosystems. Lush green ecosystems that showcase the flora and fauna available within the campus are properly preserved for general awareness and research that offer excellent opportunities for the study of complex ecosystems. This idea only can be achieved by the awareness of the university management in maintaining the health of the available ecosystem.

\section{Campus Sustainability Assessment}

The campus operation must be based on a systematic planning and operation. This will enable university management to take a more structured approach to managing resources and environmental impacts in campus. A good framework of sustainable campus is developed by Cole (2003) namely the campus sustainability assessment framework (CSAF). Cole (2003) proposes an egg of sustainability (Figure 1) that integrates of two systems which are the people and the ecosystem. In her framework, the sustainability of ecosystem covers aspect of land, water, air, materials and energy. Whereby, the sustainability of people system incorporates aspects of knowledge, community, health and wellbeing, governance, economy and wealth. Cole's framework has been adapted by many campuses around the world as it provides comprehensive framework that can be used in implementing sustainability in campus.

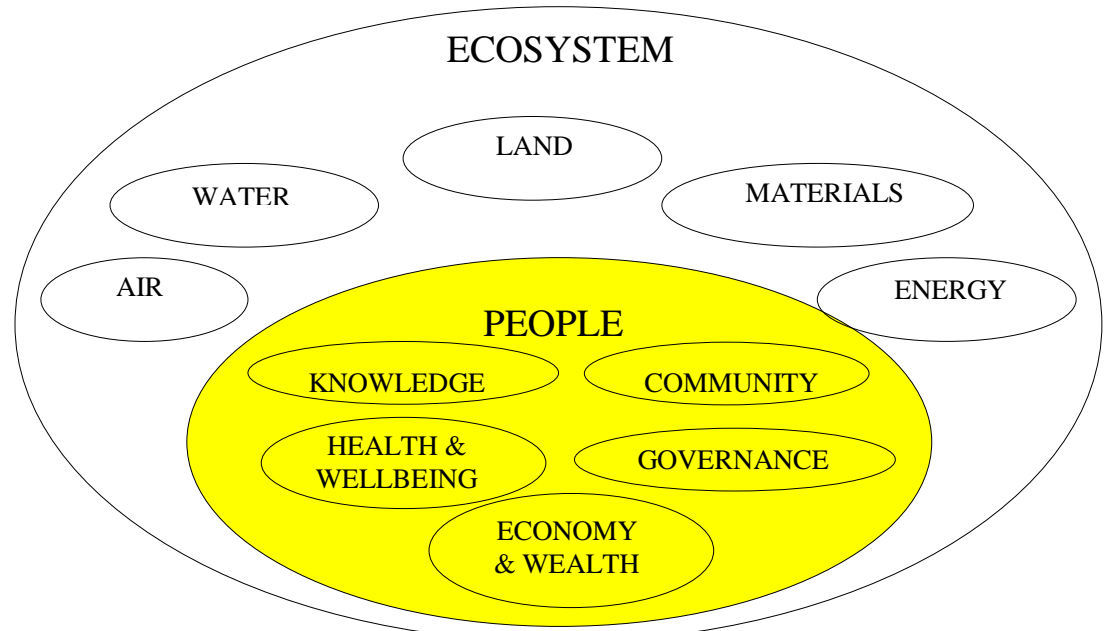

Figure 2 Egg of sustainability Source: Cole, 2003 


\section{RESEARCH METHODOLOGY}

The research employed qualitative approach using ecological site inventory, semi-structured interview and document analysis as methods of data collection. Meanwhile, the case study is chosen as the strategy of inquiry. In constructing the method, understanding on the issue of studied area, and types of information need to be collected are considered as significant. The site inventory checklist and interview questions are formulated parallel with the research questions, aim, and research objectives. The site inventory is done to understand real phenomenon of the studied area. Whereby, semi structured interview is done for two group of respondents to investigate the factors of phenomenon and verification process of framework that shows the process of selecting suitable indicators for IIUM river. Next, the data is analysed to identify major factor, critical component to be monitored and the impacts on river ecosystem. Based on the data from interview and site inventory, the process of indicator selection is proposed through thematic analysis from previous framework studied form literature review. The data are themed according to the steps of the selection of indicators. Finally the framework is verified by experts to check the appropriateness of the process and suitability of indicators.

\section{FINDINGS AND DISCUSSIONS}

The findings reveal that there are remarkable changes to the physical characteristic of river in IIUM. These have proved that there is alarming issue on the sedimentation that changes the physical character of the river, thus, influence biological and chemical properties of the river. The evidence presented in Table 1 thus far supports the idea that sedimentation resulted from anthropogenic activities has led to many consequences to the overall integrity of the river ecosystem.

Table 1 Factors of River Depletion and Its Impacts on the River Attributes

\begin{tabular}{|c|c|c|c|}
\hline Factor & Driver & Attributes & Impact \\
\hline \multirow[t]{10}{*}{ Sedimentation } & \multirow{10}{*}{$\begin{array}{l}\text { Sand mining } \\
\text { Construction } \\
\text { Erosion } \\
\text { Clogged- } \\
\text { culvert }\end{array}$} & \multirow[t]{10}{*}{ Physical } & Channel width reduction \\
\hline & & & Channel depth reduction \\
\hline & & & Channel pattern changes \\
\hline & & & $\begin{array}{l}\text { Increase slope rate that increase erosion } \\
\text { rate }\end{array}$ \\
\hline & & & $\begin{array}{l}\text { Reduce water retention capacity during } \\
\text { heavy rain }\end{array}$ \\
\hline & & & Reduce water clarity \\
\hline & & & Land degradation \\
\hline & & & Loss of reservoir capacity \\
\hline & & & Changes on the soil physical character \\
\hline & & & $\begin{array}{l}\text { New vegetation increase sedimentation } \\
\text { rate }\end{array}$ \\
\hline
\end{tabular}


Nor Zalina Harun, Mazlina Mansor, \& Safiah Abu Noh

The Benefits of River Indicators to Assess the Ecological Status of IIUM Campus

In view of factors and impacts of sedimentation, this has confirmed the significance of the study of river channel morphology in detecting changes on the ecosystem. The study reveals that physical character of the river has the strongest influence on the biological and chemical component of the river and the quality of the river are determined by the measurement of the physical character of the river. The physical form and the shape distribution to forecaster variables are somewhat simple to determine. The changes to the river channel morphology can be caused by two activities. The first factor is from anthropogenic activity modification in and surrounding the river. The second factor is from natural factor over short and long term period.

The process of selecting the suitable river indicators explained in this paper has identified river channel morphology indicator as the most suitable indicator to detect changes on the river morphology as it is the most badly affected component in IIUM.

The ability to assess the condition of the river ecosystem, evaluate sensitivity to modification, and recognize potential changes to the ecosystem resulting from different anthropogenic activities such as development adjacent to the water body is important to notify risk of river degradation for resolution making. A more systematic and sustainable approach to reduce the negative impacts of anthropogenic activities is required in making the campuses more sustainable and liveable. Although many environmental protection methods can be seen at some universities, the natural ecosystem like river is usually left unattended. One way that university management can apply in monitoring the condition of river is through the implementation of river indicators that will characterize the current situation and help determine where to focus efforts in order to make the campus ecologically sustainable.

Figure 2 explains the process of physical planning in campus organization. The monitoring process of any project or development should be implemented using ecological approach to maintain an ecologically sound environment of a campus. Accordingly, ecological approach is vital while planning for campus physical development. By promoting this approach, it will thrive for increasing environmental awareness and help to build consensus around the concept of sustainability and the need for incorporating ecological knowledge into planning. By applying river indicators for campuses that own river ecosystem, it will reduce the potential risk on the river such as river depletion, sedimentation, flood, wildlife extinction and loss of ecosystem that will further disrupt the wellbeing of the residents.

Other perceived benefits of river indicators as one process in the landscape planning process is that they convey useful information about the condition of current ecosystem so that planners can use those beneficial information in planning and maintaining campus physical ground. The integration of ecology and planning is therefore seen as multi-disciplinary 
landscape planning, in particular, to assist in helping biodiversity and development planning move away from their predominantly site-based emphasis.

(a) policies, strategies and general proposals for the development and use of county land

(b) a summary of the situational analysis

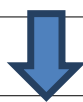

(c) proposals for proper physical development, resource utilization and linkages

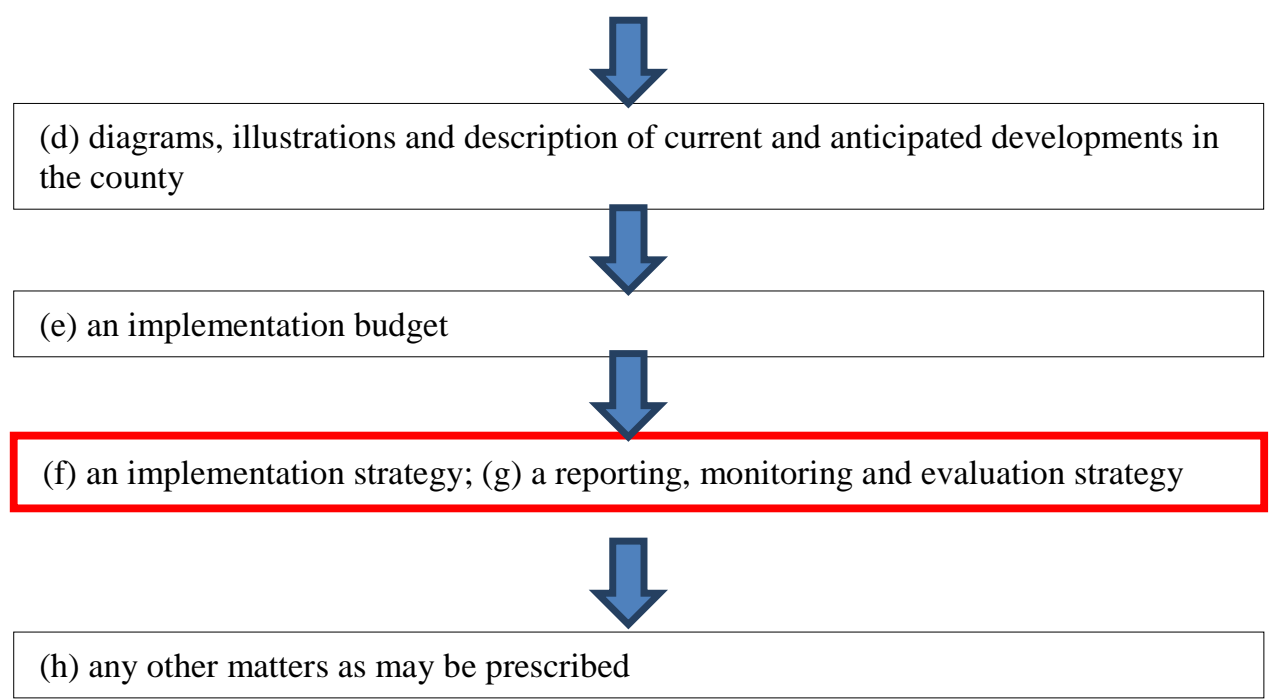

Figure 2 Campus Planning Process

\section{CONCLUSION}

The implementation of river indicator framework is emphasized because campus sustainable planning is essential and urgent in order to plan for suitable and enduring ecosystem for campus residents. Therefore, planners and landscape architects need to work harder in promoting effectively the integration of several disciplines, and incorporate ecological theory appropriately so that the campus residents can live harmoniously with nature. The research also revealed sedimentation resulted from sand mining activity, construction, erosion and clogged culvert is known as the salient factor that causes physical destruction of river ecosystem in IIUM. Therefore, maintenance and inspection are essential to 
Nor Zalina Harun, Mazlina Mansor, \& Safiah Abu Noh

The Benefits of River Indicators to Assess the Ecological Status of IIUM Campus

the successful performance of sedimentation control measures. Lack of maintenance on the river ecosystem is the most common cause of failure. Practices should be inspected on a regular basis and after each storm event. If maintenance is required, it should be performed in a timely manner to ensure proper function. Failure of a structure can release large amounts of sediment, severely impacting the river physical characteristic that later will impact the integrity of the biological and chemical attributes.

In conclusion, landscape ecology is clearly recognised as a basis for positive planning, rather than simply controlling land use on a reactive basis. Presently, in many countries in the world, there is a growing interest in integrated approach in making a campus ecologically sustainable. By applying this framework, it offers a credible basis for creating a campus a conducive place for campus residents harmonising with nature, making it sustainable for all living beings.

\section{REFERENCES}

Campos, P. (2008). Sustainable education campus in Spain - nature and architecture for training. PEB Exchange, 10, 7. DOI: 10.1787/16097548

Cole, L. (2003). Assessing sustainability on Canadian university campuses: development of a campus sustainability assessment framework. Royal Roads University.

Howitt, R. \& Rickards, S. (2013). Complete campus engagement via embedding ecological footprinting curriculum. In Proceedings of the 13th International Australasian Campuses towards Sustainability (ACTS) Conference, Sydney, Australia.

Mebratu, D. (1998). Sustainability and sustainable development. Environmental Impact Assessment Review, 18(6), 493-520.

Saadatian, O., Salleh, E., Mohd Tahir, O., \& Dola, K. (2009). Observation of sustainability practices in Malaysian research universities: highlighting particular strength. Pertanika Journal of Social Sciences \& Humanities, 17(2), 225-244.

United Nations Environment Programme. (2014). Greening universities toolkit. Retrieved from http://www.unep.org/training/docs/Greening_University_ Toolkit.pdf

World Commission on Environment and Development [WCED] (1987). Our common future. Oxford: Oxford University Press.

Zen, I. S., Bandi, M., Zakaria, R., \& Saleh, A. L. (2013). UTM sustainable campus: institutionalize sustainability, the living lab approach and sustainable energy management program. International Workshop on UI Greenmatric 2013, Depok City, Indonesia. 